\title{
Credible testimony in and out of court
}

\author{
Barbara A. Spellman And Elizabeth R. Tenney \\ University of Virginia, Charlottesville, Virginia
}

\begin{abstract}
Assessing informants' credibility is critical to several aspects of the legal process (e.g., when police interrogate suspects or jurors evaluate witnesses). There is a large body of research - from various areas of psychology and allied fields - about how people evaluate each others' credibility. We review the literature on lie detection and interpersonal perception to demonstrate that inferences regarding credibility may be multiply determined. Specifically, characteristics of the informant, of the listener, and of the situation affect people's perceptions of informants' credibility. We conclude with a discussion of research on calibration (i.e., an informant's confidenceaccuracy relation) because it offers fruitful avenues for future credibility research in the legal domain.
\end{abstract}

The quintessential courtroom scene-jurors listening intently to a lawyer questioning a witness-illustrates the importance of testimony to legal proceedings. Yet people's reliance on the testimony of others is pervasive in all sorts of everyday endeavors: We make decisions about what to do or what to buy on the basis of the advice (testimony) of others, and often, even our most basic knowledgefor example, that the earth is round-comes through the testimony of others.

What makes us choose to take the testimony of some people seriously (e.g., "there are weapons of mass destruction in Iraq") but seriously doubt the testimony of others (e.g., "this car was driven by a little old lady only to church on Sunday mornings")? Many factors affect such judgments - some consciously and some unconsciouslyincluding characteristics of the speaker, of what the speaker said, of the listener, and of the situation.

\section{Evaluating Credibility In and Out of Court}

Many rules of evidence and courtroom procedures make it clear that it is important that the trier of fact (be it a judge or a jury) should have ample opportunity to assess the veracity of witnesses. These rules and procedures are based on things as disparate as the United States Constitution and folk psychology. Jurors almost always get to see and hear witnesses as they provide testimony. That procedure is reinforced by the defendant's Sixth Amendment right "to be confronted with the witnesses against him," but courts seem to have an independent belief in the importance of jurors being able to see and assess the demeanor of all witnesses in all cases when they are testifying, as a means of assessing their credibility. The ability to cross-examine a witness on the stand is also viewed as an important means for assessing credibility. Other evidence that can be presented to jurors to help them assess credibility includes conflicting testimony by other witnesses, prior inconsistent statements by the witness, informa- tion about the witness's past conviction of certain crimes deemed to be relevant to issues of credibility, and testimony regarding the witness's reputation for truthfulness.

Although most of the rules and procedures have been investigated to some extent, the issue of how people use their own observations of an informant's characteristics and presentation style to infer credibility has garnered a huge amount of attention in the psychology literature. We first review the literature on how characteristics of the informant, of the listener, and of the situation affect credibility. Then we turn to recent research on how people use information about an informant's calibration. Calibration requires the integration of two cues to credibility: confidence and accuracy. We believe that calibration is an important, useful, and understudied cue for assessing credibility.

Note that in many of the laboratory studies reviewed here, the informants were college students or other "regular" people who were instructed to lie (or tell the truth) about things like personal opinions or the contents of a picture that they could see but the observer could not. Typically, the informants are told to lie half the time, and the participants know that the informants will lie on half the trials. Accuracy rates hover around 54\% - only slightly (and not usually significantly in single studies) above chance (C. F. Bond \& DePaulo, 2006).

\section{Characteristics of the Informant}

Research from the psychology and law literature and from the social psychology literature on persuasion and on deception agree: People judge the credibility of informants on the basis of characteristics that have no relation to their actual trustworthiness.

Basic physical characteristics can affect credibility. For example, being attractive tends to make individuals appear honest; in particular, attractiveness ratings of some specific features-baby-faceness, wide-eyeness, positivity of expression (e.g., smiling), and facial symmetry-each

B. A. Spellman, spellman@virginia.edu 
independently contribute to ratings of honesty (Zebrowitz, Voinescu, \& Collins, 1996). In addition, some people just tend to seem more trustworthy than others, and there is a consensus about who these people are (C. F. Bond \& DePaulo, 2008).

Body language, speech patterns, and other "cues to deception." People commonly believe that they can tell when others are lying by watching their behavior for telltale signs. A fascinating finding from this research is that there are, in fact, reliable cues to deception - but these are not the cues that people prefer to rely on.

People tend to rely on stereotypic cues to decide whether others are lying: For example, certain body movements (e.g., shifting positions, gaze aversion) increase beliefs that someone is being dishonest (e.g., Zuckerman, Koestner, \& Driver, 1981), and even police believe in those cues (Mann, Vrij, \& Bull, 2004). It turns out, however, that many of these "suspicious" behaviors occur as often in people telling the truth as in people lying. A comprehensive review of the literature on cues to deception (B. M. DePaulo et al., 2003) shows that many of the body movement cues that people think reveal lying, such as pauses, shifting positions, lack of eye contact, and most types of fidgeting, do not, in fact, differ between liars and truth tellers. Differences are found, however, in how information is conveyed. Liars provide less compelling accounts than do truth tellers; the lies include fewer details, are less plausible, and make less sense. Liars use fewer gestures and seem more distanced from their stories. They also correct themselves less often than truth tellers.

Perhaps because people wrongly believe in some of the more visible cues to deception, studies that compare lie detection between people who both see and hear an informant versus those who only hear an informant often show that it is better to only hear the information (C. F. Bond \& DePaulo, 2006).

Yet, even when faced with all of the informationdiagnostic or not - people do pick up on the relevant cues; they are just cautious about using them. As B. M. DePaulo and Morris (2004) explained, most studies of deception detection (both in and out of university laboratories) use direct measures; they ask participants whether statements were truths or lies, or they ask for ratings of deceptiveness. People are not much above chance on those tasks. However, when people are asked other questions, such as how ambivalent the speaker was and how comfortable they felt while listening, they respond much differently to truths and lies (i.e., they can and do distinguish them when they are not asked directly to distinguish them).

Accuracy and details. Displaying a good memorywhether verified or not-enhances credibility. Witnesses who provide detailed testimony are seen as having a sound memory and as highly credible in general, even when the details they provide are trivial-for example, specifying exactly what someone bought, instead of saying "a few store items" (Bell \& Loftus, 1989). Sensibly, witnesses who are shown to be incorrect about some informationeven trivial or secondary information-lose credibility considerably, as compared with witnesses who are not shown to be wrong about anything (Borckardt, Sprohge,
$\&$ Nash, 2003). These results, along with the results regarding confidence described next, are key to understanding why calibration is important for credibility.

Confidence. The huge research literature on confidence agrees that confidence is usually the most important factor in assessing credibility (Read, Lindsay, \& Nicholls, 1997). Displaying confidence by using powerful language and avoiding hedges and disclaimers bolsters credibility (Erickson, Lind, Johnson, \& O’Barr, 1978; Johnson \& Vinson, 1987).

However, within the huge research literature on courtroom credibility, there is a debate about whether (and when) eyewitnesses' confidence is related to their accuracy - that is, how well eyewitnesses are calibrated. We return to the issue of calibration in the final section of this article.

\section{Characteristics of the Listener}

Certain characteristics of the listener predict the listener's willingness to deem others credible, independently of others' actual behaviors and attributes. For example, people in a good mood tend to see others more favorably across the board (Forgas \& Bower, 1987), and extroverts rate expert witnesses as more credible than do introverts, possibly because extroversion is associated with more positive affect (Cramer, Brodsky, \& DeCoster, 2009).

A related empirical question is whether any personality or demographic characteristics give listeners an edge in the ability to accurately assess the veracity of others. Most research has suggested that the answer to this question is no. Assessing veracity may have two component abilities: establishing a baseline for the proportion of truths versus lies and distinguishing truth from lies.

Truth bias. Generally, there is a pervasive truth bias, which is the tendency to overassume that people are telling the truth (e.g., Zuckerman, Koestner, \& Alton, 1984). In a typical lie detection task (consisting of half true statements and half lies), participants typically overestimate the number of true statements (Levine, Park, \& McCornack, 1999). In the context of everyday encounters, the truth bias seems like an adaptive tendency, because generally people are not told life-altering lies and it eases interactions to be agreeable and trusting. In various parts of the legal process, however, the same might not be true.

In fact, research has shown that police officers and prisoners do not default to a truth bias; instead, they have a lie bias and tend to believe that people are deceptive, probably because the reward for catching a liar (e.g., protecting oneself from harm) is greater in these contexts (G. D. Bond, Malloy, Arias, Nunn, \& Thompson, 2005; Meissner $\&$ Kassin, 2002). In addition, encountering lies in prison or while interrogating suspects might be more common. However, decreased truth bias and increased general skepticism do not entail being better able to distinguish truth from lies.

Individual differences. Among the individual differences studied, education, sex, occupation, Machiavellianism, self-monitoring, locus of control, and the Big 5 personality dimensions ${ }^{1}$ have not reliably predicted people's ability to detect lies (Aamodt \& Custer, 2006; C. F. Bond \& DePaulo, 2008; Kraut, 1980; Porter, Campbell, 
Stapleton, \& Birt, 2002). However, Ekman and O'Sullivan (1991) found that U.S. Secret Service agents were much more successful than other groups, and G. D. Bond (2008) reported finding two correctional officers with over $80 \%$ accuracy.

A large-scale meta-analysis of laboratory studies showed no significant difference in lie detection performance across 247 samples of participants; variance in the ability to judge truth was no different from what would be expected by chance. The lack of variability across judges can help explain why individual differences have not been able to reliably predict success at detecting lies (C. F. Bond \& DePaulo, 2008). However, C. F. Bond and DePaulo (2008) pointed out that in real-world settings, people may differ in their ability to detect lies in certain circumstances that laboratory studies fail to capture. When people have not been forewarned that they should be on the lookout for deceit, those who are naturally more suspicious (cf. McCornack \& Levine, 1990) or who are better at reading others' motivations from situational cues and third-party informants (cf. Park, Levine, McCornack, Morrison, \& Ferrara, 2002) might be better at detecting scams.

There is some evidence that training may improve the ability to detect when specific other individuals are lying, but training does not necessarily carry over to aid in the detection of lies told by different people (Zuckerman et al., 1984).

\section{Characteristics of the Situation}

Several types of situational features are relevant to the ability to judge veracity, including the type of situation and expectations of truthfulness, the amount of attention people give to the task, and the need to justify a decision to other people.

As was described above, police officers and prisoners show less truth bias than do other people. However, in situations in which people communicate with someone they might suspect is deceptive - such as a car salesmanpeople may still be deceived, because well-practiced deceivers might learn to not give off the expected cues to deception (P. J. DePaulo \& DePaulo, 1989).

People's motivation and attention also affect their ability to detect lies and judge credibility. When under cognitive load, people pay less attention to the content of what a speaker says and are more influenced by peripheral cues - such as appearance, titles, and confidence (Petty $\&$ Cacioppo, 1986). They use such nonverbal cues (and others) to judge credibility, whereas people not under cognitive load use both nonverbal and verbal cues (Reinhard \& Sporer, 2008). Because some nonverbal cues are better indicators of deception than are many verbal cues, people who are less involved in the task of judging veracity may be better at distinguishing truth from lies (Forrest \& Feldman, 2000).

Another situational characteristic that is relevant in both real life and the courtroom is the presence of other individuals. People make different, and more cautious, decisions when they must justify decisions to others than when they do not have to do so; in particular, they make decisions that avoid ambiguity (Curley, Yates, \& Abrams,
1986). Because of the pervasive truth bias, and because the belief that someone is lying is often based on an inarticulable feeling, people may be unlikely to raise the issue of an informant's dishonesty when in a group such as a jury.

The presence of multiple informants can also affect perceptions of source credibility. For example, when a person receives a message from one informant, this informant serves as a point of comparison for all informants immediately following - even when the subsequent informants make assertions about unrelated topics. The first informant sets the stage for a standard of expertise, and moderately credible informants who testify after highly credible (vs. less credible) ones will tend to lose persuasiveness (Tormala \& Clarkson, 2007). Thus, the order in which witnesses testify will affect their credibility.

\section{Informant's Calibration}

Recent work by us and others has investigated how people use information about an informant's calibration in judging his or her credibility (Tenney, MacCoun, Spellman, \& Hastie, 2007; Tenney, Spellman, \& MacCoun, 2008). Calibration refers to the association between a person's confidence and accuracy, and we use it as a general term for two types of ability. One is an absolute measure (technically called calibration): What is the relation between the level of confidence and accuracy for individual items? Good calibration in this sense means that, for example, if someone is $70 \%$ confident about a set of events, those events will happen $70 \%$ of the time. The other is a relative measure (technically called resolution): What is the relation between confidence and accuracy across items? Good resolution means that if someone is $90 \%$ confident about a set of events, those events are more likely to happen than a set of events about which the person is only $70 \%$ confident. Resolution is measured by correlations (between confidence ratings and accuracy). The two abilities, calibration and resolution, do not always go hand in hand. For example, people can be overconfident but still show good resolution. There is research in many areas of cognitive psychology that assesses people's own calibration (e.g., reading comprehension, perceptual judgments, memory judgments, various types of predictions). There is far less research on how and when people rely on the calibration of others.

Overconfidence. Laboratory studies have shown that, in general, people are overconfident in a variety of tasksincluding their ability to detect deception (B. M. DePaulo, Charlton, Cooper, Lindsay, \& Muhlenbruck, 1997). Yet there is variability in the tendency to be overconfident. Research on individual differences in confidence has shown moderate positive correlations in confidence judgments across task domains that are not easily accounted for by task-specific cognitive explanations. For example, people who were overconfident in their assessment of their own general knowledge were also overconfident in their eyewitness identifications (Bornstein \& Zickafoose, 1999), and the same was true for people who assessed their general knowledge and also predicted their ability on a perceptual motor skills task (West \& Stanovich, 1997). 
Thus, there is some evidence that confidence level is a stable individual difference.

Confidence-accuracy correlations. As was previously mentioned, the large literature about the confidenceaccuracy relationship for eyewitnesses has mixed findings. Researchers used to claim that the relationship was quite bad (on the order of $r=.25$; this correlation is significantly above zero but probably not something on which a conviction should be entirely based); however, recent research has been more optimistic that the correlation could be higher under different, and more realistic, conditionsfor example, using within-subjects measures, having a variety of encoding conditions, and giving informants a chance to answer "I don't know" (Read et al., 1997).

There is much research on confidence-accuracy correlations in related domains; research from the memory literature is particularly relevant to the courtroom, in that it reveals factors that affect how good people will be at predicting what they will remember or reporting what they know. For example, in the feeling-of-knowing literature, people are typically asked whether they know answers to obscure general knowledge questions. Sometimes, people will say that they know the answer, even though they cannot remember it immediately. For such information, people are generally good at knowing what they know (their rating of whether they know it correlates highly with whether they later can pick out the answer on a multiple-choice test). Yet their ratings of whether they know it can be "fooled" by providing them with nonhelpful, seemingly related information (Metcalfe, Schwartz, \& Joaquim, 1993). Providing such information is somewhat like providing postevent information to eyewitnesses.

A few eyewitness studies have compared calibration for general knowledge questions and for eyewitness memory. Perfect and colleagues (e.g., Perfect \& Hollins, 1996) found that people show good resolution within subjects for both general knowledge and eyewitness memory; that is, individuals can distinguish what they remember or know well from what they do not. Bornstein and Zickafoose (1999) found not only that overconfidence was correlated across domains, but also that resolution was as well; people who were better at predicting accuracy for general knowledge were also better for eyewitness memory. In the courtroom, however, it is often necessary to contrast one witness's high-confidence assertion with another witness's less confident assertion - that is, to rely on between-subjects resolution. Across individuals, there is good between-subjects resolution for general knowledge, but not for eyewitness memory - a disturbing finding with important implications.

Calibration in the courtroom. Individual differences in confidence pose a problem for the legal system because of the great reliance that jurors place on levels of confidence in eyewitness identifications. In an ideal world, eyewitnesses would see an event, encode the important aspects of the event given the circumstances, and then bear witness to the event with the appropriate amount of confidence, given the clarity of what was encoded - and given what has happened during the intervening time that might differentially affect confidence and accuracy. Witnesses who had better viewing conditions would report more confidence than would witnesses who had degraded viewing conditions (see Deffenbacher, 1980, on the optimality hypothesis; see also Loftus, 2010). However, because witnesses vary in how over- and underconfident they are, using assertions of confidence to predict accuracy across eyewitnesses is generally unreliable.

A reasonable tactic for making confidence more informative might be to somehow gauge within-person calibration first and then adjust the credibility of informants' statements accordingly. A person shown to be overconfident about his or her general knowledge is also likely to be overconfident about his or her identification. If he or she shows good resolution in one domain, he or she is likely to show it in another (Bornstein \& Zickafoose, 1999).

Of course, there are various potential obstacles to inferring an individual's calibration, because accurately assessing calibration takes many repeated instances of confidence-accuracy pairings. In most cases (pun intended), it might be difficult to get reliable knowledge of whether an informant's statements are accurate. When they can, people are more likely to continue dealing with informants whose calibration is known, rather than deal with unknown informants (Kollock, 1994).

Using other people's calibration. We have recently shown (Tenney et al., 2007; Tenney et al., 2008) that people are willing and able to make inferences about an informant's calibration and use it to infer the reliability of other statements on the basis of only two confidenceaccuracy pairings. Our view is that confidence matters because people assume that confidence is, in fact, a good predictor of accuracy (the presumption of calibration hypothesis). However, when real information about calibration is available, people would prefer to use that information. Our participants read a story in which there were two witnesses to a target event (typically, a car accident): A, who was highly confident about his memory for the accident and for two collateral events, and B, who was highly confident about his memory for the accident, but of mixed confidence (one high, one low) for the two collateral events. Presented with this much of the story, the participants tended to believe that $\mathrm{A}$, the high-confidence witness, was more credible, and they tended to believe A's version of the accident. The participants then learned the actual facts of the collateral events; A and B were each right about one collateral event and wrong about one collateral event. In the basic condition, in which B was well calibrated (correct about his high-confidence memory; wrong about his low-confidence memory), ${ }^{2}$ the participants then switched over to believing that B was more credible, and they now believed B's version of the accident. In a control condition in which B was poorly calibrated (wrong about his high-confidence memory; correct about his low-confidence memory), people continued to prefer Witness A's account but thought neither witness was very credible. Thus, people's preference is to rely on someone who has shown good calibration in the past and who then shows high certainty about the target information. 
Our more recent research suggests that characteristics of the listener and the situation are relevant to whether calibration information will be used. For example, children (5- and 6-year-olds) do not appear to use calibration information when judging which of two people to believe (Small, Tenney, Kondrad, Jaswal, \& Spellman, 2009). Adults engaged in a divided-attention task while watching a video version of our materials fail to use calibration information as much as do adults with full attention (Tenney, Small, Jaswal, Kondrad, \& Spellman, 2009).

\section{More Questions}

There are many questions that remain for understanding how and when people do-or should - rely on informants' calibration for judging their credibility.

First, more research should be conducted to determine whether people show good resolution across various domains and what factors might affect it. We do know that calibration and resolution may be affected by expertise (Lichtenstein, Fischhoff, \& Phillips, 1982). So, if we know that someone is well calibrated in some domain, to what other domains should we generalize?

Second, regardless of the reality of calibration, what do people believe about whether others are well calibratedwithin and across domains? How much and what kind of information leads people to rely on the calibration of others?

Turning to the courtroom, court procedures generate many questions. For example, jurors are supposed to focus on the witness on the stand, but many things are going on in the courtroom, and dividing the jurors' attention might detract from their ability to gather cues to calibration. Different jurors are likely to come to different conclusions about witnesses. During deliberation, will evidence of calibration be raised, be discussed, and be persuasive? (See Salerno \& Diamond, 2010.)

And in the courtroom, jurors often do not know for a fact when witnesses are correct or not, so they cannot assess calibration. Recall that, in the courtroom, there are other procedures designed to help assess credibility. By itself, confidence might be the best predictor of whether someone will think a witness is credible, but what about cases in which there are other witnesses who disagree on facts or in which the witness changes a noncritical piece of testimony during cross-examination or is shown to previously have been convicted of a crime (such as perjury) that involves lying? There is a complicated interplay of factors that are likely to determine who we decide is worth believing - both in the courtroom and in everyday life.

\section{AUTHOR NOTE}

Correspondence concerning this article should be addressed to B. A Spellman, Department of Psychology, Unversity of Virginia, P.O. Box 400400, Charlottesville, VA 22904-4400 (e-mail: spellman@virginia.edu).

\section{REFERENCES}

Aamodt, M. G., \& Custer, H. (2006). Who can best catch a liar? A meta-analysis of individual differences in detecting deception. Forensic Examiner, 15, 6-11.
Bell, B. E., \& Loftus, E. F. (1989). Trivial persuasion in the courtroom: The power of (a few) minor details. Journal of Personality \& Social Psychology, 56, 669-679. doi:10.1037/0022-3514.56.5.669

Bond, C. F., JR., \& DePaulo, B. M. (2006). Accuracy of deception judgments. Personality \& Social Psychology Review, 3, 214-234. doi:10.1207/s15327957pspr1003_2

Bond, C. F., JR., \& DePaulo, B. M. (2008). Individual differences in detecting deception. Psychological Bulletin, 134, 477-492. doi:10.1037/0033-2909.134.4.477

Bond, G. D. (2008). Deception detection expertise. Law \& Human Behavior, 32, 339-351. doi:10.1007/s10979-007-9110-Z

Bond, G. D., Malloy, D. M., Arias, E. A., Nunn, S. N., \& Thompson, L. A. (2005). Lie-biased decision making in prison. Communication Reports, 18, 9-19. doi:10.1080/08934210500084180

Borckardt, J. J., Sprohge, E., \& Nash, M. (2003). Effects of the inclusion and refutation of peripheral details on eyewitness credibility. Journal of Applied Social Psychology, 33, 2187-2197. doi:10.1111/ j.1559-1816.2003.tb01880.x

Bornstein, B. H., \& Zickafoose, D. J. (1999). "I know I know it, I know I saw it": The stability of the confidence-accuracy relationship across domains. Journal of Experimental Psychology: Applied, 5, 7688. doi:10.1037/1076-898X.5.1.76

Cramer, R. J., Brodsky, S. L., \& DeCoster, J. (2009). Expert witness confidence and juror personality: Their impact on credibility and persuasion in the courtroom. Journal of the American Academy of Psychiatry \& Law, 37, 63-74.

Curley, S. P., YATES, J. F., \& Abrams, R. A. (1986). Psychological sources of ambiguity avoidance. Organizational Behavior \& Human Decision Processes, 38, 230-256. doi:10.1016/0749-5978(86)90018-X

DeFFEnBACHER, K. A. (1980). Eyewitness accuracy and confidence: Can we infer anything about their relationship? Law \& Human Behavior, 4, 243-260. doi:10.1007/BF01040617

DePaulo, B. M., Charlton, K., Cooper, H., Lindsay, J. J., \& MuHLENBRUCK, L. (1997). The accuracy-confidence correlation in the detection of deception. Personality \& Social Psychology Review, 1, 346-357. doi:10.1207/s15327957pspr0104_5

DePaulo, B. M., Lindsay, J. J., Malone, B. E., Muhlenbruck, L. Charlton, K., \& Cooper, H. (2003). Cues to deception. Psychological Bulletin, 129, 74-118. doi:10.1037/0033-2909.129.1.74

DePaulo, B. M., \& Morris, W. L. (2004). Discerning lies from truths: Behavioral cues to deception and the indirect pathway of intuition. In P.-A. Granhag \& L. Strömwall (Eds.), The detection of deception in forensic contexts (pp. 15-40). New York: Cambridge University Press.

DePaulo, P. J., \& DePaulo, B. M. (1989). Can deception by salespersons and customers be detected through nonverbal behavioral cues? Journal of Applied Social Psychology, 19, 1552-1577. doi:10.1111/ j.1559-1816.1989.tb01463.x

Ekman, P., \& O'Sullivan, M. (1991). Who can catch a liar? American Psychologist, 46, 913-920. doi:10.1037/0003-066X.46.9.913

Erickson, B., Lind, E. A., Johnson, B. C., \& O'BARr, W. M. (1978) Speech style and impression formation in a court setting: The effects of "powerful" and "powerless" speech. Journal of Experimental Social Psychology, 14, 266-279. doi:10.1016/0022-1031(78)90015-X

Forgas, J. P., \& Bower, G. H. (1987). Mood effects on personperception judgments. Journal of Personality \& Social Psychology, 53, 53-60. doi:10.1037/0022-3514.53.1.53

ForRest, J.A., \& FeldMan, R. S. (2000). Detecting deception and judge's involvement: Lower task involvement leads to better lie detection. Personality \& Social Psychology Bulletin, 26, 118-125. doi:10.1177/ 0146167200261011

John, O. P., \& Srivastava, S. (1999). The Big Five trait taxonomy: History, measurement, and theoretical perspectives. In L. A. Pervin \& O. P. John (Eds.), Handbook of personality: Theory and research (2nd ed., pp. 102-138). New York: Guilford.

Johnson, C., \& Vinson, L. (1987). "Damned if you do, damned if you don't?": Status, powerful speech, and evaluations of female witnesses. Women's Studies in Communication, 10, 37-44.

Kollock, P. (1994). The emergence of exchange structures: An experimental study of uncertainty, commitment, and trust. American Journal of Sociology, 100, 313-345. doi:10.1086/230539

Kraut, R. E. (1980). Humans as lie detectors: Some second thoughts. Journal of Communication, 30, 209-216. 
Levine, T. R., Park, H. S., \& McCornack, S. A. (1999). Accuracy in detecting truths and lies: Documenting the "veracity effect." Communication Monographs, 66, 125-144.

Lichtenstein, S., Fischhoff, B., \& Phillips, L. D. (1982). Calibration of probabilities: The state of the art to 1980. In D. Kahneman, P. Slovic, \& A. Tversky (Eds.), Judgment under uncertainty: Heuristics and biases (pp. 306-334). New York: Cambridge University Press.

Loftus, G. R. (2010). What can a perception memory expert tell a jury? Psychonomic Bulletin \& Review, 17, 143-148.

Mann, S., VRIJ, A., \& Bull, R. (2004). Detecting true lies: Police officers' ability to detect suspects' lies. Journal of Applied Psychology, 89, 137-149. doi:10.1037/0021-9010.89.1.137

McCoRnACK, S. A., \& LeVIne, T. R. (1990). When lovers become leery: The relationship between suspicion and accuracy in detecting deception. Communication Monographs, 67, 219-230.

Meissner, C. A., \& Kassin, S. M. (2002). "He's guilty!" Investigator bias in judgments of truth and deception. Law \& Human Behavior, 26, 469-480. doi:10.1023/A:1020278620751

Metcalfe, J., Schwartz, B. L., \& Joaquim, S. G. (1993). The cuefamiliarity heuristic in metacognition. Journal of Experimental Psychology: Learning, Memory, \& Cognition, 19, 851-864. doi:10.1037/0278 $-7393.19 .4 .851$

Park, H. S., Levine, T. R., McCornack, S. A., Morrison, K., \& FerRARA, M. (2002). How people really detect lies. Communication Monographs, 69, 144-157.

Perfect, T. J., \& Hollins, T. S. (1996). Predictive feeling of knowing judgements and postdictive confidence judgements in eyewitness memory and general knowledge. Applied Cognitive Psychology, 10, 371-382. doi:10.1002/(SICI)1099-0720(199610)10:5<371::AID -ACP389>3.0.CO;2-O

Petty, R. E., \& CAcioppo, J. T. (1986). The elaboration likelihood model of persuasion. In L. Berkowitz (Ed.), Advances in experimental social psychology (Vol. 19, pp. 123-205). New York: Academic Press.

Porter, S., Campbell, M. A., Stapleton, J., \& Birt, A. R. (2002). The influence of judge, target, and stimulus characteristics on the accuracy of detecting deceit. Canadian Journal of Behavioural Science, 34, 172-185. doi:10.1037/h0087170

Read, J. D., Lindsay, D. S., \& Nicholls, T. (1997). The relation between confidence and accuracy in eyewitness identification studies: Is the conclusion changing? In C. P. Thompson, D. J. Herrmann, J. D. Read, D. Bruce, D. G. Payne, \& M. P. Toglia (Eds.), Eyewitness memory: Theoretical and applied perspectives (pp. 107-130). Mahwah, NJ: Erlbaum.

Reinhard, M., \& SPORER, S. L. (2008). Verbal and nonverbal behaviour as a basis for credibility attribution: The impact of task involvement and cognitive capacity. Journal of Experimental Social Psychology, 44, 477-488. doi:10.1016/j.jesp.2007.07.012

Salerno, J. M., \& Diamond, S. S. (2010). The promise of a cognitive perspective on jury deliberation. Psychonomic Bulletin \& Review, 17, 174-179

Small, J. E., Tenney, E. R., Kondrad, R. L., Jaswal, V. K., \& SpellMAN, B. A. (2009, April). Young children use accuracy and confidence, but not calibration, when judging credibility. Poster presented at the 2009 Society for Research in Child Development (SRCD) Biennial Meeting, Denver.

Tenney, E. R., MacCoun, R. J., Spellman, B. A., \& Hastie, R. (2007). Calibration trumps confidence as a basis for witness credibility. Psychological Science, 18, 46-50. doi:10.1111/j.1467-9280.2007 .01847.x

Tenney, E. R., Small, J. E., Jaswal, V. K., Kondrad, R. L., \& SpellMAN, B. A. (2009). Accuracy, confidence, and calibration: How young children and adults assess credibility. Unpublished manuscript.

Tenney, E. R., Spellman, B. A., \& MacCoun, R. J. (2008). The benefits of knowing what you know (and what you don't): How calibration affects credibility. Journal of Experimental Social Psychology, 44, 1368-1375. doi:10.1016/j.jesp.2008.04.006

Tormala, Z. L., \& Clarkson, J. J. (2007). Assimilation and contrast in persuasion: The effects of source credibility in multiple message situations. Personality \& Social Psychology Bulletin, 33, 559-571. doi: $10.1177 / 0146167206296955$

West, R. F., \& Stanovich, K. E. (1997). The domain specificity and generality of overconfidence: Individual differences in performance estimation bias. Psychonomic Bulletin \& Review, 4, 387-392.

Zebrowitz, L. A., Voinescu, L., \& Collins, M. A. (1996). "Wideeyed" and "crooked-faced": Determinants of perceived and real honesty across the life span. Personality \& Social Psychology Bulletin, 12, 1258-1269. doi:10.1177/01461672962212006

Zuckerman, M., Koestner, R., \& Alton, A. O. (1984). Learning to detect deception. Journal of Personality \& Social Psychology, 46 519-528. doi:10.1037/0022-3514.46.3.519

Zuckerman, M., Koestner, R., \& Driver, R. (1981). Beliefs about cues associated with deception. Journal of Nonverbal Behavior, 6, 105-114. doi:10.1007/BF00987286

\section{NOTES}

1. The Big 5 personality dimensions are broad, comprehensive dimensions of personality that were developed to provide a common language for describing personality. The dimensions are extraversion, agreeableness, conscientiousness, neuroticism, and openness to experience. See John and Srivastava (1999) for a review.

2. We acknowledge that technically, our "well-calibrated" witness shows good resolution, not good calibration.

(Manuscript received July 27, 2009 revision accepted for publication October 8, 2009.) 